\title{
Erratum: Education hubs and private higher education expansion in small island developing states contexts: The case of Mauritius
}

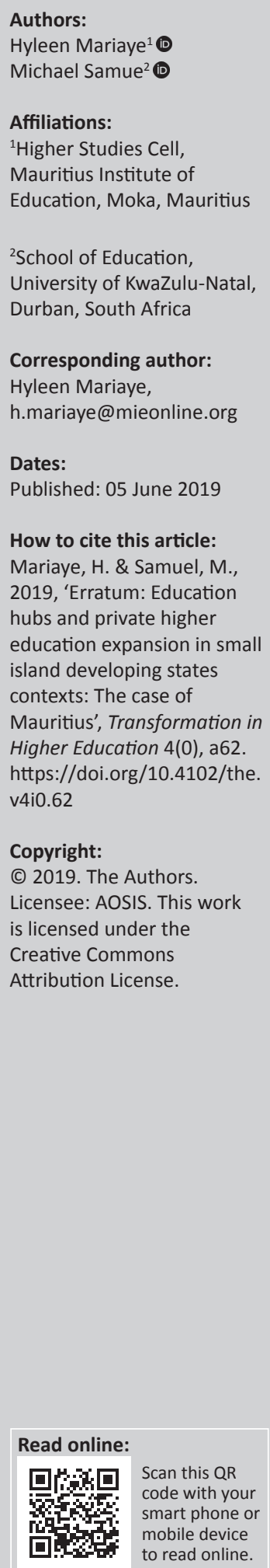

This article published in volume 3 was incorrectly categorised as a Review Article. The article category is hereby corrected as Original Research. This correction does not alter the study's findings of significance or overall interpretation of the study results. The editor apologises for any inconvenience caused. 


\section{Education hubs and private higher education expansion in small island developing states contexts: The case of Mauritius}

\begin{tabular}{|c|c|}
\hline \multicolumn{2}{|c|}{$\begin{array}{l}\text { Authors: } \\
\text { Hyleen Mariaye }{ }^{1} \text { (1) } \\
\text { Michael Samuel }^{2} \text { ( }\end{array}$} \\
\hline \multicolumn{2}{|c|}{$\begin{array}{l}\text { Affiliations: } \\
{ }^{1} \text { Higher Studies Cell, } \\
\text { Mauritius Institute of } \\
\text { Education, Mauritius }\end{array}$} \\
\hline \multicolumn{2}{|c|}{$\begin{array}{l}{ }^{2} \text { School of Education, } \\
\text { University of KwaZulu-Natal, } \\
\text { South Africa }\end{array}$} \\
\hline \multicolumn{2}{|c|}{$\begin{array}{l}\text { Corresponding author: } \\
\text { Hyleen Mariaye, } \\
\text { h.mariaye@mieonline.org }\end{array}$} \\
\hline $\begin{array}{l}\text { Dates: } \\
\text { Received: } 01 \\
\text { Accepted: } 31 \\
\text { Published: } 16\end{array}$ & $\begin{array}{l}\text { May } 2018 \\
\text { uly } 2018 \\
\text { Oct. } 2018\end{array}$ \\
\hline \multicolumn{2}{|c|}{$\begin{array}{l}\text { How to cite this article: } \\
\text { Mariaye, H. \& Samuel, M., } \\
2018 \text {, 'Education hubs and } \\
\text { private higher education } \\
\text { expansion in small island } \\
\text { developing states contexts: } \\
\text { The case of Mauritius', } \\
\text { Transformation in Higher } \\
\text { Education } 3(0) \text {, a46. https:// } \\
\text { doi.org/10.4102/the.v3i0.46 }\end{array}$} \\
\hline \multicolumn{2}{|c|}{$\begin{array}{l}\text { Copyright: } \\
\text { (c) 2018. The Authors. } \\
\text { Licensee: AOSIS. This w } \\
\text { is licensed under the } \\
\text { Creative Commons } \\
\text { Attribution License. }\end{array}$} \\
\hline \multicolumn{2}{|l|}{ Read online: } \\
\hline 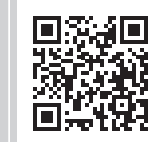 & $\begin{array}{l}\text { Scan this QR } \\
\text { code with your } \\
\text { smart phone or } \\
\text { mobile device } \\
\text { to read online. }\end{array}$ \\
\hline
\end{tabular}

Background: This article is located in the context of governments of small island developing states supporting education hubs in collaboration with local and global partners. Whilst current literature on the development of education hubs focuses on the macro policy perspectives looking at how education hub policies are designed and enacted upon at national level, there are relatively few studies on the micro perspective of the institutions.

Aim: By comparing the agendas, experiences, potential and drawbacks of these institutions, the article explores the sustainability prospects of these variants of education hubs.

Methods: We selected three case studies: a public distance education university, a local private university and an international branch university within the same broader environmental context to examine how a 'vision of possibilities' is played out within three different institutional agendas.

Results: The case studies reveal that marketisation and privatisation marginalise the pursuit of quality which recedes in preference for securing international economic resources to activate the local developmental agendas and how the exercise privileges skewed power relations which maintain centre-periphery hegemonic hierarchies in the cross-border collaborations.

Conclusion: The uptake of an education hub as a national target exemplifies how the uncritical and indiscriminate borrowing of policies normalises and is reframed to appear as 'moments of equity'. But in reality it promotes individual competitiveness at the expense of the common good.

\section{Introduction}

The discourse on higher education is increasingly dominated by the language of econometrics, whereby global competitiveness, branding and investment have carved a niche for themselves. This turn in the philosophy and approach which sets up higher education as a private good has been initiated in the leading economies of the North by the downscaling of government's financial support to public universities, which forced them to import a business model into the domain of higher education (Blessinger \& Makhanya 2018). This paradigmatic shift in state policies regarding higher education was motivated by a critique that higher education accrues benefits primarily to the individual in terms of higher learning prospects and, as such, the burden of finance should therefore rest with the individual rather than the state.

However, this change on its own could not have triggered the massive transformation currently being witnessed in higher education the world over. The internationalisation of higher education defined by Knight (2004:11) as 'the process of integrating an international, intercultural and global dimension into the purpose functions (primarily teaching or learning, research, service) or delivery of higher education' in a large measure, supports the shifts observed. Today, two out of every 100 higher education students are studying outside their country of origin either as expatriates or as international students. The trend in student mobility worldwide, coupled with the noted correlation between rise in income and demand for higher education, has assisted to recast higher education as an area of development of its own. Research increasingly highlights the benefits to be reaped by promoting all forms of international education, even when it is internationalisation 'at home' (Knight 2013a).

A number of countries have responded by considering the opportunities offered in the emergent global higher education scenario to position themselves as regional and international leaders in 
the provision of higher education services (Knight 2011). Asian education hubs such as Singapore and Hong Kong are cited as success stories, illustrating how democratisation of access to higher education and the leveraging of higher quality human resources could activate economic development. Whilst the policy of internationalisation of higher education takes diverse forms depending on the priorities, approaches and strategies adopted by governments in response to the economic, political and social realities of national contexts, they are invariably born out of deliberate long-term initiatives of the government to build a critical mass of operators in the higher education sector.

The leading countries which have met success in graduating from transnational education to the academic internationalisation of their higher education sector through their foreign staff and student recruitment, policies and programmes are the UAE, Singapore, Malaysia and Hong Kong. Other countries such as Botswana, Vietnam and Mauritius are now also vying to position themselves as regional higher education centres to earn dividends from the internationalisation of higher education in terms of attracting foreign direct investment, building a skilled labour force and earning revenue whilst absorbing the rising local demand resulting from rise in income levels (Sharma 2011). The relative importance of these factors varies as per national agendas. For example, Middle East countries' governments invested frontally and massively in building state-of-the-art infrastructure to attract leading universities to build capacity and generate what is referred to as 'soft power', or as Knight (2013b) puts it, 'diplomacy'. South East Asian countries have been proactively diversifying their portfolio and source markets seeking to take advantage of the increase in demand that is likely to primarily come from China in the next few decades (Bayley 2016). These successes have generated an uptake of the policy in a number of countries whose fiscal, legal and work environments have been synchronised to ease off the entry of foreign providers in their higher education sector.

However, whilst the success of this policy borrowing is measured exclusively in quantitative terms, namely international student recruitment, league table universities and the number of branch campuses (UniRank 2018), dissonant voices highlight the risks associated with the unbridled commercialisation of cross-border education and reflect on the social commitment that public higher education is expected to demonstrate to national development agendas (Samuel 2017; see also Odora-Hoppers 2002). Others are concerned with the impact cross-border provisions will have on indigenous systems of higher education and the weakening of the intercultural dimension of internationalisation in the face of economic considerations (Chikoko 2016). Homogenisation, rendered necessary in the name of equivalence, can result in internationalisation becoming exclusively a process of status-building and acquiring an increasing market share at the expense of the values internationalisation stand for, such as mutual benefits, capacity building and partnerships (Knight 2013).

Whilst there exist in the literature global and general explanations as to how education hubs may hover somewhere between a real innovation with transformative economic and political potential and a rhetoric or fad (Knight 2011), there is no documentation of case studies of institutions within the same national context. These are not only valuable because their narratives uncover the ground realities but also conceptually significant as they illuminate how sustainability issues are related to different modes of knowledge, leadership, learning and capacity building (Richards 2018). These narratives need to be made explicit in the continued conversation with policymakers to transform a 'vision of possibilities' into a 'threshold' of change (Richards 2018).

Through the experience of the three case studies representing each a variation in policy enactment, namely a branch campus, a private university and a public university dispensing on distance mode, we address not only the operational question of how is the policy being implemented, but also the question how the macro pillars of internationalisation, privatisation, and marketisation are being integrated into the micro pillars of quality, affordability and infrastructure. Whilst the global discourse may focus on the benefits that may arise for encouraging the internationalisation of higher education on the grounds that it can create a more level playing field for all to benefit, we question the power equation involved in pursuit of the privatisation of higher education provisions through education hubs. We interrogate how the expansion of higher education provision simply denotes a change of form in the power relations between centre and periphery, perhaps on similar patterns of the past extractive economies where the centre retains control over quality assurance whilst still benefitting from the use of resources in peripheries. The end point reflective commentary engages in the current debate of the purposes of higher education.

\section{Higher education in Mauritius at a glance}

The Mauritian tertiary education sector has almost a century long history with the setting up of the College of Agriculture in 1923. As at 2016, 10 publicly funded tertiary education institutions and 37 private post-secondary institutions are operational. An additional 17 private bodies are registered but they are not considered to be fully operational as they do not have any student enrolment of registered courses (Tertiary Education Commission 2017).

The statistics on tertiary education participation rates have plateaued since 2014 and declined further from $47 \%$ to $46 \%$ in a year with a total of some 38178 students registered in local institutions and 9911 studying abroad. New admissions have stagnated within the range of 13 000-14 000 since 2007, indicating that the policy initiatives to radically improve 
uptake both locally and internationally have not yet yielded expected results (Tertiary Education Commission 2017). The University of Mauritius slid in its ranking in Africa's top 100 to the 73rd place (UniRank 2018).

In terms of internationalisation of the student population, the 100000 students from abroad targeted by the education hub policy paper seems like a lofty target with a current grand total of 1736 (TEC 2017), the bulk of whom comes from India, 692 of whom are currently registered in the medical school or courses offered on a Mauritian campus. Nigeria and South Africa also attract some 200 students, but again this is primarily in the medicine, hospitality, engineering and computer science sectors.

The freshly set up Médine Education Village from the cane corporate giant, the Médine Group, hosts a number of international institutions in its 35-hectare Unicity and has positioned itself as a key player in the higher education sector. The city aims to welcome 5000 students by 2025, out of which $75 \%$ are expected to be international students as compared to its current 1700 students registered in 19 undergraduate courses with eight foreign institutions (Médine 2018).

\section{The history of an idea: Mauritius education hub in context}

The desire to make Mauritius an education hub is almost two decades old, although the idea was formally launched in 2006 with the publication of the Sectoral Committee Report by the Human Resource Development Council. Basically, it inhabited public discourse for more than a decade before concrete shape was given to it. The document provides the following rationale which underpins till date the opening sections of almost all policy documentation related to education. It was believed that:

If Mauritius wants to position itself as a knowledge hub and as a key player in the Region, considerable emphasis should be laid on the postsecondary education sector, making it of a worldclass status, in order to attract international students, reputable institutions of higher learning and highly qualified academics and researchers worldwide. (Human Resource Development Council 2007a:10)

The strategy was articulated around setting the island postsecondary sector as a regional pole for quality higher education by reinforcing local public universities through international partnerships and by giving tax incentives to foreign providers of higher education.

The policy for setting up Mauritius as an education hub was further developed in the Review of National Human Resource Development Plan (2007-2010). Recognising the growing role of knowledge in the economy through the growth of Knowledge Processes Outsourcing (KPO) as a major economic activity and the subsequent demands this will place on skill development locally, the document highlights the key role that the knowledge hub will play in positioning the island in the USD 17 billion market that KPO represented in 2010.

The strategies stood on eight pillars defining the set of enabling conditions to allow the project to take off. They relate to the setting up of a Regulatory Framework Recognition that is a 'flexible facilitating framework, which fosters innovation, the fluid sharing of knowledge and the creation of linkages amongst institutions and enterprises' (HRDC 2007a:14); with proper processes of accreditation; the guarantee of quality of education to ensure the robustness of reputation; the setting up of appropriate infrastructure and the provision of a package of incentives such as land concession rates, double taxation relief and loans to institutions at preferential rates. Improving the efficiency of the local feeder system in terms of the output from the secondary school sector was signalled as pre-requisite for ensuring that local demand will be sustained. This was coupled with the adoption of a system of Continuing Performance.

Development would ensure that the constant need of professional development would equally generate sustainable local demand for higher education. Viewed as a strength that would attract both Francophone and Anglophone institutions and international students, multilingualism and language competencies were to be given special attention. Lastly, because the education hub was expected to also generate new ideas, products and processes, a legal framework for regulating Intellectual Property Rights was to be set up (HRDC 2007b).

Many of these measures were inspired by the experiences of countries like Malaysia which started off their internationalisation process by actively encouraging private providers to set up shop and partner up with foreign universities. However, the policy of the education hub was also driven by the government belief that Mauritius is economically, politically and geographically ideally positioned to act as intermediate between African and Asian students seeking an international qualification and European universities seeking to expand their activities in new territories (Clark 2015).

Since the official uptake of this policy through the Board of Investment (BOI), national investment promotion agency, partnerships developed and private institutions were set up. The number of international students on Mauritian campuses increased to a total of 1736 international students from 69 different source countries - an increase of 13.9\% over 2015 figures (TEC 2016). This statistic has to be read in conjunction with the targeted aim of a 100000 foreign students. Whilst there is a clear tendency to see the glass as half-full by policymakers, Mauritian ambitions have been sobered by problems encountered at the implementation stages that relate to the quality assurance of the awards with no less than 11 institutions as at 2014 losing their authorisation to operate. Others, like Aberystwyth branch campus, closed operations last year (2017). 


\section{Literature review}

The emergence of education hubs represents a new generation of cross-border activities allowing for more people, programme and policy mobility. Knight (2013a) conceptualises education hubs as:

a concerted effort by a country or (city or zone) to build a critical mass of local and international actors to strengthen its effort to build a higher education sector, expand the talent pool or contribute to the knowledge economy. (p. 375)

She further identifies three different models of education hubs: the student hub, the talent hub and a knowledge or innovation hub (Knight 2013a). Although the objectives, scope and impact of each of these differ, the common denominator appears to be the interaction and connectedness amongst local and international actors rather than the geographical location. Education hubs are viewed as an important cogwheel in a network society of information flows primarily between urban (or cosmopolitan) and professional centres.

Richards (2018) argues that the inherent tension experienced by education hubs remains the need to reconcile short-term efficiency and long-term resilience. The experience of South East Asian hubs like Singapore, where the provision of highquality infrastructure and an adequately credentialed international staff served to establish reputation, has been cited as an example of a 'broker' approach where the hope was for the country to act as an intermediary for western providers of high-quality higher education in the region. The Malaysian education hub is, on the contrary, cited as initially one that reflected more of an effort to improve accessibility and affordability of higher education, given the large local demand for higher education (Ka Ha Mok 2011). The policy used in these two cases are diametrically opposed, with one focusing on high-end and elitist provisions for both local and international students and the other adopting a more muddled approach inspired initially by nationalistic ambitions (Ka Ha Mok 2011) to position itself as a regional centre for knowledge and innovation with a focus on highquality capacity development.

Irrespective of the model, integrating national capacity development plans into the education hub policy requires a framework that harmonises the micro requirements of infrastructure, affordability and quality with the imperatives of privatisation, internationalisation and marketisation. These vary greatly depending on the obstacles and restraints experienced in each context, as well as on the modes of knowledge, learning and leadership, academic integrity, culture of openness and inclusivity in place (Richards 2018).

Whilst there exist substantial comparative literature on education hubs, these have focused on cross-national comparisons in terms of policy enactment with two or more country-level cases (Dou \& Knight 2014; Ka Ha Mok 2011; Knight 2011). It is our view that the lens of these studies focuses on the macro enactment rather than on what Richards (2018) terms the 'corridor of policy emergence', which is the critical space where macro-level policy and its discourses are understood, interpreted, mediated and translated into action at an institutional level. This is where the present study expects to make a contribution.

The purpose of this study is to:

- Develop an understanding of how organisations, within an emergent education hub, integrated internationalisation, marketisation and privatisation with the tripartite imperatives of affordability, quality and infrastructure.

- Analyse whether current institutional enactments of an education hub reflect a model of asymmetric or dialogical economic, cultural and epistemological relationship.

The first research question is attended to in the case-to-case presentation section which illustrates how each aspect is uniquely negotiated and integrated in the vision, functioning and challenges of each institution. We respond to the second question in the discussion section.

\section{Three case studies}

As highlighted above, the current study falls within the tradition of case study approach in research. This approach has been usually applied in the exploration of education hubs but more at the national levels and often in a comparative mode. Country-level studies are useful for policy evaluation in a global stance but do not allow for those at the receiving end of the policy to comment and provide insights as to the issues in policy deployment at the micro level.

Because our aim was to read the policy from multiple perspectives and from a bottom-up level, we selected three institutions whose organisational objectives and structures are varied enough to produce distinct responses to macro influences. The first one is a public distance education institution which is a major player in the education hub strategy, the second is the longest lasting private higher education institution in Mauritius with a full-fledged campus, and lastly, we included a private provider which was consecutively the branch campus of an Indian and two British Universities in the past decade and which finally closed operations last year.

\section{Case study methodology}

We deploy the case study methodology in a bid to reach contextualised explanations. We argue along the same line as Welch et al. (2011) that using a critical realist posture can enable theorisation from case studies.

The strength of the case study methodology lies in the in-depth knowledge it generates based on multiple sources. In the context of this study three sources were used, namely the website of each respective institute that details out the mission, vision and history, as well as the documents related 
to the institution such as its strategic plan, external audit reports and newsletters. We also consulted reports and official policy documents in relation to the policy of the education hub. An interview with the head or director of each institution was carried out to discuss the position and experience of their organisation with respect to the policy. We factor in a combination of all these elements and conditions found in each case to produce a 'configurational' and 'conjunctural' perspective (Welch et al. 2011) as the macro and micro factors may operate differently in the unique context of the individual cases.

More importantly, one of the authors has been professionally involved with two of the organisations as a member of the Accreditation panel for one of their provisions. The fact that higher education in a small island state is a close-knit context makes professional interaction amongst members of different institutions inevitable. The positionality of one of the researchers enabled not only access to the leaders but also professional trust that facilitated an authentic attitude and response to the questions posed. Each interview lasted for between $30 \mathrm{~min}$ to 1 hour.

\section{Data presentation}

We chose a case-by-case presentation and depart from the usual thematic approach. The intention is to capture the uniqueness of each institution as a player within the same broader framework of an education hub (itself a component of a broader knowledge hub), the challenges experienced, the strategic choices and the reflective postures of each head of institution or director on how they envision their role in the emergent hub.

We constructed the case around the issues identified in the reflective interviews, which speak strongly to the twin sets of concerns that have been highlighted in the literature, namely marketisation, internationalisation and privatisation, and affordability, quality and infrastructure, although these are not equally present in all the three cases.

The documentation drawn from websites, plans and organisational documents available in the public domain have been subject to content analysis, the outcomes of which have been woven in the presentation to support or challenge the points raised in the interviews. From this perspective, the cases are not merely presented but also simultaneously analysed through the authorial commentary that runs throughout.

\section{The place of a national distance education university in an education hub: The Open University of Mauritius}

The Open University of Mauritius (OU) was established on 12 July 2012 and absorbed the defunct Mauritius College of the Air which had been in operation for almost three decades. It is a distance university currently servicing some 3578 students (TEC 2017). It offers courses from undergraduate to $\mathrm{PhD}$ level, having some 180 students registered on postgraduate degree programmes. The human resource model used to staff the university is minimalist with the majority of them being on contract (TEC 2015).

The data gesture very strongly towards an understanding of the critical role open universities play in achieving two stated agendas of education hubs: expanding local higher education provisions beyond domestic frontiers and contributing to the development of a skilled workforce through the provision of continuous professional development programmes in a variety of domains. As all open universities, its target clientele extends to students whose needs may not be met by the more traditional residential universities and who thus will engage in professional or academic learning using the more convenient and flexible patterns of engagement with studies offered by distance modes of learning. From foundation courses designed to offer a minimum academic requirement to those who need a second chance for pursuing their higher studies up to doctoral level, the university constructs its mission primarily on widening access.

The ambitions of OU are aptly captured in its statement of Goal number 6 of its strategic plan 2017-2015: 'Ensure that $\mathrm{OU}$ is the first choice, locally and regionally, for continuous professional development and lifelong learning' (Open University of Mauritius 2017).

It also acknowledges the competitive environments created by Massive Open Online Courses (MOOCs) whilst also drawing from the success of similar institutions in larger nations like the University of South Africa (UNISA) and the Indira Gandhi Open University, India. In its quest for ascertaining reputation and quality, an ISO certification has been obtained and been used as a marketing strategy to claim a larger share in the open market (Open University of Mauritius 2017). With a student population standing at 3578, out of the 9370 Mauritian nationals studying by distance mode (TEC 2017), the OU currently occupies a third of the total distance enrolments and about $10 \%$ of all tertiary enrolments.

Its strategy of partnering with renowned institutions is not primarily for joint awards but as an inbuilt system of quality assurance. Taking the assistance of high-calibre universities in the design and delivery of both award and non-award courses is a strategic branding move as an international player. Such moves must be understood in the context of its intention to 'Establish six overseas study centres (Rodrigues, Kenya, Tanzania, Uganda, Rwanda and Botswana) and ensure that all learners of $\mathrm{OU}$ have the same learning experience' (Open University [OU] 2017:22).

One of the aims of this national university is also to become financially autonomous so as to be able, amongst others, to engage in high-quality research as enunciated in its strategic plan. The issue of finance has been repeatedly mentioned in the strategic plan and in the interview with the head of 
the institution. The comment regarding the financing and staffing issues being met by the institution was made during the interview indicating how challenging it is at institutional level to navigate the troublesome terrain of policy, discourse and practice.

There appears to be a general understanding on the part of policymakers in the Ministry of Education that public institutions must make do with what they can mobilise as resources whilst still being audited on the entire spectrum of policy goals set by governments. One poignant example given relates to quality recognition and accreditation by foreign partners of the Open University courses which had to be eventually dropped as a branding option because of the very high costs involved. Although the impact of this setback has not been articulated clearly, it will mean that the institution will have to stand on the strength of its own reputation to attract students from the African continent. Whilst its fees are competitive with respect to northern providers, it will clearly be at a disadvantage with providers like UNISA and other emergent distance universities on the African continent whose governments are more financially supportive.

The use of scholarships was evoked as a strategy to make Mauritius known as a higher education destination. Fifty scholarships were offered to prospective candidates of the African continent to 'advertise' the institution. Only 20 scholarships were awarded to candidates from countries like Botswana and Namibia whilst the remaining 30 were never attributed because there were fewer eligible applicants than expected. Indeed, it is the strong belief of the participant that some cohesion must be achieved by all those involved in the sector by federating all higher education providers under one brand. He argued that Mauritius needs to 'catch up' on South East Asian hubs by encouraging local providers to develop expertise in specific fields.

Research is also flagged as one area of development in the strategic plan of the OU, as outlined in Goal 14 (see box 1).

The enrolment on research degrees has reached a total of approximately 800 enrolments, with 171 doctoral candidates. However, the 2015 Audit report reveals that:

Most of the supervisors appointed by OU are not research-active and some of them have no publications in peer-reviewed journals or conferences. For MPhil and doctoral supervision, the research proposals of the MPhil/PhD student should be related to the research fields of the supervisors. More so being given that most of the main supervisors are from outside, it is still more imperative to have the second local supervisor to be in the same field as the research proposal of the MPhil/PhD students so that he/she can supervise the students on a day-to-day basis ... At present several of the local supervisors are not research-active and have not published any research papers for years or have not published at all. (TEC 2015:15)
BOX 1: Goal 14 Effective research, consultancy and innovation.

14.1 Finalise the organigram of the Research, Consultancy and Innovation (RCI)
Unit and get the appropriate staff to man the Unit.
14.2 Create a critical mass of researchers and consultants in key development areas.
14.3 Open avenues to secure funding for research-related activities at OU.
14.4 Organise workshops, conferences and other research-related activities.
14.5 Collaborate with journal publishers and tertiary and cultural institutions,
nationally and internationally.
14.6 Breed a culture of innovation in OU research projects.
14.7 Set up research hubs in key research areas.
14.8 Provide consultancy services to national and international organisations.
14.9 Develop research-based studies leading to Master's and Doctoral degrees'.

Source: Open University of Mauritius 2017:21

The provision of higher research degrees is premised on the ability of the institution to develop research capacities. However, the above comment from the audit panel clearly highlights the capacity issues to effectively provide the supervisory services at this level.

Although the pathway to establish the OU as a key player on the African continent appears to be clearly defined in the strategic plan and the discourse held, its effectiveness is severely compromised by the financial realities of the institution as well as an underestimation of human resource capacity requirement necessary to guarantee the quality of postgraduate provisions.

\section{Charles Telfair Institute: From local private university to branch campus}

Founded in 1999 as the De Chazal du Mée Business School, Charles Telfair Institute (CTI) kick-started operations with 232 students reading to become chartered accountants and IT engineers. It is now the alma mater of some 9000 graduates and currently housed in a state-of-the-art complex at the centre of the island (CTI 2014). Being one amongst the first private institutions of higher learning, it enjoys a solid reputation which has been painstakingly constructed over its nearly two decades of existence. Part of the process of settling within the higher education landscape was considerably eased by its affiliation to two Australian universities, namely Curtin University and North and South Metropolitan University in Western Australia. Currently, according to their website, 27 courses are offered from Certificate to Master's level, with the bulk of student registration at degree level. Eleven international students are on the CTI campus, indicating that in essence, it is primarily a private local university.

CTI is one of the success cases of private higher education in terms of longevity and student outcomes, emerging out of a fully local consortium of the private sector that predates the enunciation of the policy of an education hub. In fact, the view expressed by the representative conveys much of the scepticism around whether the policy of the knowledge hub is leading to a coherent, cohesive and federated strategy from the private sector, which, it was argued, appeared to be operating individually in isolation. The creation of a signature for Mauritian higher education would be a desirable objective to enable the realisation of the government vision but more strategically integrated moves are required in the same way 
that Perth as a city has been transformed to accommodate higher education students, he argued. The view expressed also seems to suggest that a naive view of the knowledge hub is being enacted. A parallel was drawn with the evolution of Mauritius as a tourist hub, whereby stakeholders in the field never acted in synchrony but operated in isolation, promoting themselves rather than Mauritius as a destination. The case of the Médine Education Village or UNICITI was referred to not as an evidence of unity of strategy and actions but rather as part of a property development project by the ex-sugarcane consortium which wishes to recycle its operation and land freed from sugar plantation into what is perceived as a lucrative business.

The branding strategy, though targeting the African continent, suffers from a major weakness. The participant was of the view that Mauritius appears to offer very little as an 'African destination'. 'We become different things at different times depending on the requirements'. This, he believed, deprived Mauritians of an identity. It is claimed that a progressive strategy of development has been adopted, where CTI built on its strength and took on in a phased manner the challenges of providing quality in higher education.

'We have grown from strength to strength building slowly to be able to reach where we are', commented one of the founding members. The data from the website and the interview corroborate to indicate that partnership, majorly with the University of Curtin, was an important factor to allow the institution to improve its quality processes. But, in parallel, the institution wanted to create a signature for higher education and this is what the proponents suggest has been the hallmark of success for CTI. 'We have a high pass rate, almost $85 \%$ because we work individually with students'. The reason provided to explain the success rate lies in the pedagogical approach which is individualised and the support given in terms of tutorials. An examination of the website and other online documents reveals that the campus provides some diversity in terms of student experience as well as a voice to students.

However, even in the face of these efforts and the current success in local recruitment, CTI fares less well on the internationalisation of its student population. Despite the declared discourse of success of CTI in asserting its presence locally, the setting up of the Médine Educational village and its host of prestigious European partners with French Higher education providers which offer courses at reasonable rates will no doubt make the field even more competitive.

The strategic reaction has been to convert CTI fully into a branch campus of the University of Curtin. This move is constructed as enabling positive conditions for growth and development. It appears that the option of becoming a branch campus was the most viable lifeline, opening up the African continent for prospective students. Playing in a more international terrain requires literally being handheld by a stronger more internationally reputed university.
The implications of being a branch campus extends well beyond the programmatic requirements of having a course accredited: it involves considerable loss of autonomy and the compulsory adherence to certain administrative, financial, academic and procedural norms set by the international accrediting institution. This is not seen, or at least projected, as an issue for CTI. Rather, the gains have been highlighted and the move to becoming a branch campus considered as progress because of the institutional upscaling that it entails in terms of quality assurance processes and upgrading of staff research profiles. The latter is mainly achieved through provision of a doctoral learning opportunity for staff who are in majority reading for a $\mathrm{PhD}$ with the OU. The added advantage is that CTI management will sit on the executive board on a large and reputable university like Curtin and shape its policy as the gatekeeper to the African continent. More so, autonomy will be retained in terms of staffing the local campus, marketing Curtin on the African continent and managing its own finances. It appears, technically, that not an ounce of autonomy is lost, apart perhaps, that CTI is now at the service of a product which is no longer its own, as all programmes will be exclusively Curtin's academic courses. This compromise is seen as positive by the managers of CTI because students (local and international) see the gaining of a degree qualification as not aiming to serve parochial jurisdictions but rather as an international passport and a prospective economic migration too. The localised indigenous knowledge content of the curriculum offered in other courses not previously accredited by Curtin University is not seen as a significant loss. The move to convert CTI to a branch campus is set up in the discourse as a deliberate choice by the founding members who are no doubt answerable to the 17 shareholders in terms of making the institution lucrative. Only time will tell what is gained and lost in terms of an indigenous higher education project.

\section{Aberystwyth University Branch Campus Mauritius}

More than the case of Aberystwyth, it is the trajectory of the local partner, the Boston Institute which is of interest. Operating under different names and with a variety of foreign partners such as Wolverhampton through the last decade, the private operator made several attempts to provide international programmes to local and foreign students until Aberystwyth decided not to enrol any more students this year.

The private operator draws funding from a private trust created by a local family currently running a private secondary school in the eastern part of the island. Its first attempt to venture in higher education was through a partnership with a private university in Sikkim, the Eastern Institute for Integrated Learning in Management (EIILM). It had already 400 students on campus when the Tertiary Education Commission instructed the branch campus to put an end to recruitment because EIILM did not receive the mandatory clearance certificate from the higher education regulatory body in India, the University Grants Commission (Balan 2015). 
The second attempt of partnership of the trust was with the University of Wolverhampton branch campus in 2012. The course offerings spanned undergraduate and postgraduate provisions in law, sports and education. Closure of this satellite campus occurred after nearly 4 years of operation with an intake of only 140 students. In 2014, the vision for the Mauritius campus was then expressed in terms of becoming the African hub for Wolverhampton and providing an international experience to both staff and students of the university (Morgan 2015).

The Aberystwyth branch campus was set up in 2015 amidst significant controversy in the home country. Aberystwyth University hall residences were being closed in Wales for want of funding whilst the university incurred a loss of $£ 200000$ in the first year in collaboration with Boston campus, the local partnering institution. Nevertheless, the branch university operated for 2 years recruiting in the past year some 50 students of whom 11 were foreign nationals. The total number of students was 106 in 2 years of operation on a campus designed to accommodate 2000 students. The courses on offer spanned computer science to law degrees, awarded by an institution that stands in the top five in the United Kingdom and thus had considerable appeal to both a local and an international audience.

The reflective interview with the head of all these three affiliated branch campuses took the participant back to the initial calculation that led policymakers to adopt the vision of making Mauritius a knowledge hub. He commented that at the time, the logic was fairly straightforward. Based on the global market figures for higher education and the accelerated growth rate expected from the African continent particularly, it was estimated that the prospects of the island attracting 100000 international students was considered as achievable, given the political and economic stability of the context, and thus the potential for revenue generation provided the impetus.

The claim is made that the parameters defined and clearly articulated in the policy document are not efficiently enacted upon by the various government agencies. Actually, he alluded to the fact that the procedural provisions are not investor friendly because accreditation requires for the campus to be completely functional at the time of application for accreditation. The risk, he argues is borne by the investor who could have his application rejected on very minor issues regarding, for example the mandatory size of open spaces on the campus.

One way to mitigate these risks was to partner up with universities of high repute in the North, which he did with Aberystwyth. The motives of the Welsh university to set up a branch campus in Mauritius need to be understood in the financially constrained context of the Brexit, which meant that alternatives to keep up student recruitment were explored. Brexit had the impact of a declining international student enrolment which had to be reversed.
Because of the advantageous ranking of Aberystwyth University in the United Kingdom, it attracted the top performers of the secondary school sector in Mauritius. The fees were high but this was deemed to be the attraction for students who would still access the best UK universities on Mauritius campus using the technological facilities available on the online learning platform, which was considered by the participant as cutting edge. The projection that 200 students enrolled on the campus would make it profitable as the fees were equally shared between Boston Institute and the home university. The latter was expected to bring its share of student recruitment but never did.

The participant referred to the aspect of the policy for which the BOI had a leadership role in constructing three state-ofthe-art campuses which was to be leased out to external highcalibre providers of higher education. The BOI organised road shows to try and sell Mauritius as an attractive destination for those universities who were looking to conquer the African continent. Yet, two of these full-fledged campuses are being converted, one into a nursing education facility because there have been no takers of the facilities (BOI 2018).

Commenting on the relative success of other branch campuses, the participant is of the view that many of them adapted to the requirements of the market they wished to penetrate offering tailor-made programmes to allow students to quickly upgrade qualifications. As for the local population, the low response rate, according to him is because of a culture of free higher education that has set in since the postindependence era. 'Paying for Higher education is something Mauritians are not used to!' he argued, as an explanation for the low Mauritian student uptake for quality private higher education that comes with a price tag.

The above comment reflects a legitimate question as to whether open privatisation, as the one adopted in the Mauritian context is warranted given the culture of free tertiary education that was established in the aftermath of independence. Clearly, organisational conceptions of quality and affordability were not coherent with dominant local cultural expectations of private higher education.

\section{Discussion}

The combination of ambitious internationalisation, open privatisation and top-down marketisation adopted, enacted and described impacted directly on the micro pillars of quality, affordability and infrastructure. The top-down approach adopted by the government to cash in on what it saw as a rapidly expanding market on the African continent has produced, at the institutional level, two sets of responses. Firstly, a purely business response to an opportunity for benefitting from government support in terms of tax reliefs, loan opportunities and quick dividends to set up private higher education institutions. This approach has attracted a number of operators who have scanty understanding of quality assurance processes in higher education and 
knowledge of the profile, expectations and aspirations of students, the management of teaching and learning, and the more technical processes of accreditation and recognition. They became compliant parties in their relationship with external partners. Over time, the leadership role that was initially attributed to the private sector to spearhead the education hub in terms of exemplary infrastructure and setting up of sustainable partnerships with foreign institutions of repute came to a premature end as a number of them exited the system within 3 years of operation.

In the second instance, the government constructed its role exclusively in terms of setting up the legal operational framework and three model campuses to be rented by foreign partners. The more technical aspects of setting up the education hub was transferred to an independent agency which was itself learning its role as a regulator of the sector which was intended to be increasingly privatised. More significantly, the top-down model of internationalisation could potentially ensure that proper infrastructure become accessible and a range of opportunities are offered at affordable fees but these do not necessarily guarantee the success of the model if the quality of student (international) learning experiences is not considered as a key ingredient. The notion of quality could be extended to how entrepreneurial higher education institutions can be in developing scholarship and an inclusive academic culture which values dialogue, social openness and cross-cultural inclusivity. The question is whether a top-down approach to internationalisation can include systemic interventions to initiate and support changed practice.

The uptake of a top-down approach to marketisation and an open policy on privatisation as internationalisation imperative does pose some challenges as to how quality is constructed and mediated. One set of responses seem to indicate that there are no external referents for the quality of awards and as indicated in one case, the partnering institutions have a great degree of latitude to design curriculum for award courses to meet the candidate at entry point. Whilst it could be viewed as an instance of inclusive academic practice for collaborative institutions, it could also be symptomatic of the compulsion to solely sustain recruitment.

The other scenario is that the local private university strategically hands over the responsibility for quality assuring its awards to the external partner. The process of quality assurance then also integrates infrastructure-related dimensions. This is a possible marketisation strategy that trumps the affordability card whilst signalling that the high costs are accounted for in the validation processes with the parent university.

The institutional accommodations of the policy of the education hub exemplified in the three case studies do not reflect an expanded form of academic, economic, social and political convergence based on the principle of reciprocity and inclusivity.
In terms of capacity, mobility and collaboration, little is currently witnessed to give confidence that it is not only the interest of the elite which is served within small island states through education hubs. The narrower definition of internationalisation of education appears to be predominant as borrowed indiscriminately from the successful experience of South East Asian hubs. We posit that South East Asian hubs like those developed in Singapore and Malaysia do not necessarily contribute to the global integration model that education hubs are supposed to promote. Instead, the alternative of importing knowledge and providers is used in the same way private firms operating in developing contexts resource the units with technical labour from the home country. Just as in an economic model where the luxury of using time to develop local capacity is too onerous to afford, education hubs operate independently of local systems of education or even at the cost of local higher education systems if the gap is considered too large. This analysis very much resonates with the experience of the branch campus of Aberystwyth whereby the home partner was used primarily as a recruitment agency and to guarantee that technical and physical set up are adequate. The home institution involvement in the curricular aspects is quasi non-existent or are wholly determined and managed by the foreign provider as a means of quality assurance. The register is one of complete conformity that serves to meet the demands of a clientele intent on having exactly the same product as the home market. Any difference in curriculum content or approach that is the outcome of discussion between partners is perceived as working against the credentialing of the courses of private institutions.

The above described situation is strangely akin to colonial contexts, an antithesis to the ongoing discourse of dialogue, mutual benefit and intercultural sharing that constituted the strong philosophical roots of internationalisation (Sanders 2018). The vexing question is whether this epistemological relationship between North and South will follow the same pattern of technological transfer that was experienced in the last century, where products of lower quality were sold on the developing world markets even by the best providers in the developed world. Such issues have started to emerge with some of the degrees awarded in Mauritius not recognised as a full-fledged UK degree in the home country.

Although the shutting down of branch campuses is not the exclusivity of small island contexts like Mauritius, the experience of the above-mentioned trust in running three branch campuses which were all shut down because of the low levels of student enrolment, does foreground the issue of critical evaluation by policymakers when choosing and determining the type of institutions selected and the terms of reference of partnerships being negotiated. Such caution exercised at the time of selection would ensure than both local institutions are encouraged to broaden the parameters of negotiation with their partners to look beyond the purely utilitarian perspective. In a small island state where the odds for economic survival are slim, producing intense competition for a restricted market, it is understandable that 
any policy which promises to expand markets and possibilities would seduce both government and local private operators. Such patterns of indiscriminate compliance work against the local higher education sector, which overlook critical aspects of higher education partnerships such as the development of an agenda for research and capacity building. However, it does seem to us that private sector providers who may not have been part of academia themselves could have been insufficiently informed about the nuances and understandings required to negotiate more productive terms of collaboration.

More so, what does the current pattern of paying for scholars and experts to achieve some form of internationalisation reflect in terms of equity issues for those who depend primarily on the local public higher education system? Creating the required infrastructure that will service the purpose of private providers means taking resources away from consolidating public higher education sectors. However, within the current discourses of privatisation, any action of the government that is seen to support a more resilient and confident public higher education system is regarded as nationalistic and, as such, a weakness.

If the performance of local higher education leaves much to be desired in terms of quality, then perhaps in the first instance, these must be repaired by a more robust support of the quality of teaching and learning within these institutions, achieved by means of partnerships whose mandates may not be caught up in the stranglehold of numbers. In Mauritius, such partnerships exist since 1999 and have slowly flourished to produce a range of outcomes based on mutual benefit and collaboration. The histories of such partnerships have been marginalised and are under fire because they look more like boutique provisions that do not sit with the econometric motivation of being an education hub which seeks to homogenise and control the responses and aspirations of actors to fit primarily current demands and expectations. Partnering institutions from more developed contexts are equally not nurturing academic relationships that may bring qualitative benefits in terms of staff development and research outputs if these are not supported by strong financial gains in terms of student recruitment.

\section{Conclusion}

This study sets out to examine how three higher education Institutions in Mauritius interpreted, mediated and enacted declared intentions of setting up Mauritius as a regional education hub on the African continent. The caveats of this policy as translated in the individual institutional experiences have highlighted the extent to which policy borrowing can serve to undermine emergent local efforts to create a national signature based on developing an indigenous, scholarly, collective, collaborative and culturally open approach to higher education. This would be a stronger foundation for negotiation and authentic partnerships with foreign institutions that could further the research and innovation agenda.
The findings also revealed how commercialisation of crossborder provisions has engendered a diversity of responses in both public and private institutions. They are survival responses rather than strategic ones, aimed at preserving financial integrity in the short-term. When faced with a level playing field, public universities, dispossessed of government funding must generate new ways of existence that are antithetical to the very political reasons that saw their establishment.

Walker (2006), applying Sen's capability theory to the analysis of the development of higher education, is of the view that it should aim at developing new ways of understanding the world and one's place in it. She contends that the education hub is an example of how knowledge production and knowledge societies have produced a 'workable' compromise involving skilling of human resource and intellectual inquiry. Walker (2006) further argues that universities' mission of critical citizenry achieved by means of development of intercultural capability and human solidarity is being discounted. The data reveal that the entrepreneurial agenda of possibilities is a form of prospecting economic exploration and 'market opportunity'. However, the economic rhetoric may be masked in the declared claims to support the interest in advancing research or knowledge production. This disguise might also be communicated in policy rhetoric of affording expanding access to higher education of previously excluded individuals or groups.

The uptake of an education hub as a national target exemplifies how the uncritical and indiscriminate borrowing of policies normalises and is reframed to appear as 'moments of equity'. Just as the national policies of the marine hub and the medical hub were heralded as opening new vistas of possibilities for progress and success for all, the education hub promotes competitiveness at the level of individuals.

We argue that, generally, the experience of cross-border provisions reflects narrow and exploitative patterns of relationships between local and international providers. Local providers and governments capitulate to the agendas of shortterm profit, prestige and status often at the expense of more sustainable forms of progress in both the quality of higher education and participation rates. Massive resources in the case of Mauritius have been and continue to be invested in an area which requires a concerted effort and more critical realism to allow higher education to be increasingly integrated in the research and development projects of industries. More importantly, at the moment there is scanty evidence even that significant headway has been made in enabling higher education to allow the kinds of connectivities within various sectors of the economy or achieve more equity of access to those who need it either locally or on the continent. More political clarity is needed to imaginatively consider ways in which we can affirm values that relate to the achievement of the common good. 


\section{Acknowledgements Competing interests}

The authors declare that they have no financial or personal relationships which may have inappropriately influenced them in writing this article.

\section{Authors' contributions}

H.M. was the project leader and S.M. conceptualised and edited the article.

\section{References}

Balan, G., 2015, 'Mauritius: The rising moon of higher learning', Edubeanz, viewed 12 March 2018, from http://www.edubeanz.com/?p=1337

Bayley, C., 2016, 'International student recruitment analysis and review - Emerging opportunities in 2016', WEBA World Education Review, viewed 21 March 2018, from http://webaworld.com/emergingopportunities.pdf

Blessinger, P. \& Makhanya, M., 2018, 'Issue No: 491 Towards higher education in service of humanity', University World News, viewed 21 March 2018, from http:// www.universityworldnews.com/article.php?story=20180130100345559

Board of Investment (BOI), 2018, Information on projects, viewed 31 March 2018 , from http://www.investmauritius.com/Projects/

Charles Telfair Institute (CTI), 2014, CTI chronicles, viewed 25 March 2018, from http://www.telfair.ac.mu/news/downloads/apr14.pdf

Chikoko, V., 2016, 'Issues in Africanising higher education curricula', in V. Msila \& M.T. Gumbo (eds.), Africanising the curriculum: Indigenous perspectives and theories, pp. 71-82, SUNMeDIA, Stellenbosch, South Africa.

Clark, N., 2015, 'Established and emerging hubs for international education in Africa and the Middle East', Strategic Internationalization, viewed 18 April 2018, from https://wenr.wes.org/2015/06/established-emerging-hubs-internationaleducation-africa-middle-east

Dou, L. \& Knight, J., 2014, 'Emerging hubs: South Korea, Sri Lanka, Mauritius, and Bahrain', in J. Knight (ed.) International education hubs: Student, talent, knowledge-innovation models, pp. 165-182, Springer, Dordrecht, Netherlands.

Education Policy and Data Center (EDPC), 2014, Mauritius National Education Profile viewed 19 March 2018, from https://www.epdc.org/education-data-research/ mauritius-national-education-profile

Human Resource Development Council (HRDC), 2007a, 'Chapter 9: The education sector: Towards a knowledge hub', National Human Resource Development Plan (NHDRDP), viewed 25 March 2018, from http://www.hrdc.mu/index.php/ downloads/category/12-nhrdp-1-2007

Human Resource Development Council (HRDC), 2007b, 'Report of sectoral committee on emerging sectors', Sectoral Committee Reports, viewed 12 March 2018, from http://www.hrdc.mu/index.php/publications/sectoral-committee-reports

Ka Ho Mok, J., 2011, 'The quest for regional hub of education: Growing heterarchies, organizational hybridization, and new governance in Singapore and Malaysia, Journal of Education Policy 26(1), 61-81. https://doi.org/10.1080/02680939.2010 .498900
Knight, J., 2004, 'Internationalization remodeled: Definition, approaches, and rationales', Journal of Studies in International Education 8(1), 5-31. https://doi. org/10.1177/1028315303260832

Knight, J., 2011, 'Education hubs: A fad, a brand, an innovation?', Journal of Studies in International Education 15(3), 221-240. https://doi.org/10.1177/10283153 11398046

Knight, J., 2012, 'Concepts, rationales, and interpretive frameworks in the internationalization of higher education', in D.K. Deardorff, H.D. Wit, J.D. Heyl \& T. Adams (eds.), The SAGE handbook of international higher education, pp. 27-42, Sage, Thousand Oaks, CA.

Knight, J., 2013a, 'Education hubs: International, regional and local dimensions of scale and scope', Comparative Education 49(3), 374-387. https://doi.org/10.1080 /03050068.2013.803783

Knight, J., 2013b, 'The changing landscape of higher education internationalisation - For better or worse?', Perspectives: Policy and Practice in Higher Education 17(3), 84-90.

Médine, UNICITI Education Hub, viewed 21 March 2018, from http://www.medine. com/our-activities/education

Morgan, J., 2015, 'Wolverhampton to shut down Mauritius campus', Times Higher Education, viewed 04 April 2018, from https://www.timeshighereducation.com/ news/wolverhampton-shut-down-mauritius-campus

Odora-Hoppers, C.A., 2002, Indigenous knowledge and the integration of knowledge systems: Towards a philosophy of articulation, New Africa Books, Claremont, South Africa.

Open University (OU), 2017, Strategic planning 2017-2025 abridged version Mauritius, viewed 30 March 2018, from http://www.open.ac.mu/sites/default/ files/abridged_ou_strategic_plan_2017-2025_uncontrolled_document-min.pdf

Richards, C., 2018, 'Higher education privatisation, internationalisation and marketisation: Singaporean versus Malaysian models of Asian education hub policy', Compare: A Journal of Comparative and International Education. https:// doi.org/10.1080/03057925.2017.1413638

Samuel, M.A., 2017, 'Africanising the curriculum: indigenous perspectives and theories by Vuyisile Msila \& Mishack T. Gumbo (Editors)', Educational Research for Social Change 6, 87-92.

Sanders, J.S., 2018, 'National internationalisation of higher education policy in Singapore and Japan: Context and competition', Compare: A Journal of Comparative and International Education 52, 1-17. https://doi.org/10.1080/03057925.2017.1417025

Sharma, Y., 2011, 'Issue No: 63 Asia: Countries vying to become education hubs', University World News, viewed 21 March 2018, from http://www. universityworldnews.com/article.php?story $=20110318130607540$

Tertiary Education Commission (TEC), 2015, Quality assurance report Open University of Mauritius, viewed 31 March 2018, from http://www.tec.mu/pdf_downloads/ pubrep/oureportfinal_080116.pdf

Tertiary Education Commission (TEC), 2016, Participation in tertiary education 2015 viewed 31 March 2018, from http://www.tec.mu/pdf_downloads/pubrep/ Participation\%20inTertiary\%20Education\%202015_130916.pdf

Tertiary Education Commission (TEC), 2017, Participation in tertiary education 2016 , viewed 31 March 2018, from http://www.tec.mu/pdf_downloads/pubrep/ Participation\%20in\%20Tertiary\%20Education\%202016.pdf

UniRank, 2018, Top 200 universities in Africa: 2018 African University Ranking, viewed 30 March 2018, from https://www.4icu.org/top-universities-africa/

Walker, M., 2006, 'Towards a capability-based theory of social justice for education policy-making', Journal of Education Policy 21(2), 163-185. https://doi. org/10.1080/02680930500500245

Welch, C., Piekkari, R., Plakoyiannaki, E. \& Paavilainen-Mäntymäki, E., 2011 'Theorising from case studies: Towards a pluralist future for international busines research', Journal of International Business Studies 42(5), 740-762. https://doi. org/10.1057/jibs.2010.55 